\title{
Septo-Optic Dysplasia
}

National Institute of Neurological Disorders and Stroke (NINDS)

\section{Source}

National Institute of Neurological Disorders and Stroke (NINDS). Septo-Optic Dysplasia

Information Page.

Septo-optic dysplasia (SOD) is a rare disorder characterized by abnormal development of the optic disk, pituitary deficiencies, and often agenesis (absence) of the septum pellucidum (the part of the brain that separates the anterior horns or the lateral ventricles of the brain). Symptoms may include blindness in one or both eyes, pupil dilation in response to light, nystagmus (a rapid, involuntary to-and-fro movement of the eyes), inward and outward deviation of the eyes, hypotonia (low muscle tone), and hormonal problems. Seizures may also occur. In a few cases, jaundice (prolonged yellow skin discoloration) may occur at birth. Intellectual problems vary in severity among individuals. While some children with SOD have normal intelligence, others have learning disabilities. Most, however, are developmentally delayed due to vision impairment or neurological problems. 